\title{
EL ROL UNIFORMADOR DE LA JURISPRUDENCIA DE LA SALA PENAL DE LA CORTE SUPREMA: ANATOMÍA DE UN FRACASO*
}

\author{
Jaime Couso Salas ${ }^{* *}$
}

RESUMEN

El relativo fracaso de la Sala Penal de la Corte Suprema en el cumplimiento de su objetivo de uniformar la jurisprudencia se asocia a los déficit de condiciones culturales, institucionales y de técnica jurídica asociados, en la experiencia comparada, al logro de esa misión. La existencia de una sala especializada en materia penal, con miembros más o menos estables en el tiempo, es una sola de esas condiciones que no logra, por sí sola, compensar el déficit de aquellas otras.

$$
\text { JURISPRUDENCIA - PRECEDENTES - CORTE SUPREMA }
$$

\section{The unifying role of precedents from the supreme court's criminal division: Anatomy of a failure}

\begin{abstract}
The Supreme Court's Criminal Chamber has mostly failed in the fulfillment of its task of unifying the case law. This result is associated to the lack of certain cultural and institutional conditions -and the legal-reasoning skills, that make that task possible in some other legal systems. The sole existence of a Criminal Chamber is one condition, but not enough to compensate the lack of the other ones.
\end{abstract}

\section{CASE LAW - PRECEDENTS - SUPREME COURT}

* Este trabajo fue elaborado en el marco Proyecto de Investigación "Jurisprudencia de la Sala Penal de la Corte Suprema", con el apoyo del Fondo Nacional de Investigación en Ciencia y Tecnología, de Chile (Proyecto $\mathrm{N}^{\circ}$ 1030167), dirigido por el autor y desarrollado conjuntamente con Jorge Mera. El autor agradece la inestimable colaboración del Profesor Álvaro Castro, quien se desempeñó como investigador asistente de este Proyecto

Abogado, Doctor en Derecho, Profesor de Derecho penal de la Facultad de Derecho de la Universidad Diego Portales, Av. República 105, Santiago, Chile; jaime.couso@udp.cl Artículo recibido el 8 de junio de 2007 y aceptado para su publicación por el Comité Editorial el 22 de octubre de 2007. 


\section{INTRODUCCIÓN}

$\mathrm{E}$ 1 rol de uniformación de la jurisprudencia, asignado a la Sala Penal de la Corte Suprema desde su creación en $1995,{ }^{1}$ no ha podido cumplirse de forma satisfactoria, por lo menos no durante los primeros ocho años de funcionamiento de esa sala especializada. ${ }^{2}$ Esta deficiencia se aprecia tanto en el caso de la llamada "uniformación vertical”, que supone que las cortes de apelaciones (y los tribunales de instancia) sigan en forma más o menos regular los "precedentes" de la Sala Penal, como respecto de lo que puede denominarse "uniformación interna”, que significa que la misma Sala resuelva regularmente los casos de que conoce en forma consistente con las doctrinas que ella misma ha aplicado en el pasado en casos semejantes. ${ }^{3}$

La explicación de estos resultados es compleja, como lo es en realidad la práctica de seguimiento de precedentes, asociada tan estrechamente al cumplimiento exitoso de la tarea de uniformación de jurisprudencia.

Este trabajo se propone explicar el relativo fracaso de la Sala Penal en el cumplimiento de esa tarea. Para ello será necesario en primer lugar explicar con cierto detalle, atendiendo para ello a la experiencia de otros países, en qué consiste la práctica de seguimiento de precedentes y qué condiciones la hacen posible, así como los demás mecanismos institucionales con que otros sistemas jurídicos intentan promover una aplicación uniforme (y, por ello, cierta y previsible) de la ley penal (apartado I). En segundo lugar, y sobre la base de esa perspectiva, que ofrecerá el marco teórico desde el cual juzgar los datos relativos a la situación chilena, se abordará precisamente un análisis de las condiciones institucionales y de la cultura judicial chilena, que explican que nuestros tribunales, y la Sala Penal en particular, no hayan logrado, durante prácticamente la primera década de existencia de ésta última, cumplir con esta importante tarea definida al momento de su creación (apartado II). Para ello se tiene en cuenta la perspectiva aportada por actores fundamentales del sistema judicial chileno. ${ }^{4}$

${ }^{1}$ Véase Mera, J., "La Corte Suprema y el establecimiento de precedentes en materia penal”, artículo inédito presentado a discusión en el Centro de Investigaciones Jurídicas de la Universidad Diego Portales, Santiago de Chile, posteriormente incluido como estudio preliminar en Mera, J. y Castro, A., Jurisprudencia penal de la Corte Suprema, LexisNexis, Santiago, Chile, 2007.

${ }^{2}$ Véase Couso, J. y Mera, J., "El rol uniformador de la jurisprudencia de la Sala Penal de la Corte Suprema. Estudio empírico”, en Ius et Praxis, Vol. 1, 2007 (en prensa), estudio que, precisamente, se concentra en el período 1995-2002, sin perjuicio de ofrecer una cierta perspectiva de la situación hasta el año 2005, fecha de las últimas entrevistas realizadas en el marco de esa investigación.

${ }^{3}$ Ibídem.

${ }^{4}$ A través de entrevistas realizadas en el marco de la investigación que dio origen a este trabajo (véase supra, nota al pie *), a ministros de la Corte Suprema, de las cortes de apelaciones y a abogados penalistas y profesores de Derecho penal y de un Taller de Discusión con ministros de cortes de apelaciones y abogados. La especificación metodológica de estas actividades se encuentra en Couso y Mera, op. cit. 


\section{Seguimiento DE PRECEDENTES Y CONDiCiONES INSTITUCiONALES} PARA LA UNIFORMACIÓN DE LA JURISPRUDENCIA ${ }^{5}$

\section{Seguimiento de precedentes en el common law y en los sistemas jurídicos continentales. Una necesaria desmitificación}

Una diferencia que tradicionalmente se señala entre los sistemas jurídicos que aplican el common law y los sistemas jurídicos continentales se refiere al uso de los precedentes judiciales. En los primeros, los precedentes serían vinculantes para los jueces que decidan en el futuro un asunto semejante, y la jurisprudencia constituiría, de esa manera, una fuente del derecho, junto con la ley y la costumbre; en los segundos, en cambio, los precedentes no tendrían más que un mero valor ilustrativo, las sentencias sólo producirían efectos en la causa para la cual se pronunciaron y la jurisprudencia no constituiría una fuente del derecho, siendo la ley -en algunas ramas del derecho, junto a la costumbre- la fuente por excelencia.

Pero la verdad es que las prácticas judiciales en torno al uso de precedentes, en diversos países tradicionalmente asociados a esos dos sistemas, manifiestan niveles de convergencia incompatibles con la distinción categorial en la que se apoya aquel retrato: en ambos sistemas los precedentes son empleados por los tribunales y tienen diversos grados de fuerza vinculante. ${ }^{6}$

Sin embargo, hay un área donde la tradición jurídica continental ha enfatizado con especial celo la exclusión de los precedentes vinculantes y el papel virtualmente exclusivo de la legislación (y, en medida muy menor, de la costumbre) como fuente del derecho: el Derecho penal. El principio de legalidad penal, incorporado en todas las constituciones que siguen aquella tradición, sería el punto de apoyo para esa resistencia del Derecho penal frente al avance del sistema de precedentes, que parece estar colonizando al derecho civil y muchas de sus ramas autónomas en los sistemas jurídicos continentales. La aplicación de precedentes vinculantes y el desarrollo de un derecho jurisprudencial en materia penal en los países que siguen el common law, a menudo es visto desde la tradición continental con cierta desconfianza y como una negación del principio de reserva de ley, en conformidad con el cual la jurisprudencia no puede tener fuerza vinculante en esta jurisdicción, pues la única fuente legítima, constitucionalmente autorizada para crear Derecho sería la ley. Así lo ha entendido la Corte Suprema chilena cuando se ha planteado el problema. ${ }^{7}$

${ }^{5}$ Este apartado resume, en parte, ideas desarrolladas con mayor detalle en el estudio realizado por Couso, J., "El uso de precedentes en materia penal: retórica y realidad en perspectiva”, en Revista General de Derecho Penal (www.iustel.com, RGDP), $\mathrm{N}^{\circ} 5$, mayo de 2006, pp. 5 y ss.

${ }^{6}$ Es la conclusión que se desprende de la comprehensiva investigación coordinada por MacCormick y Summers (Eds.), Interpreting Precedents. A comparative Study, Aldershot-Brookfield-Singapore-Sydney: Ashgate/Dartmouth, 1997.

${ }^{7}$ La Corte Suprema chilena ha apelado al argumento de las fuentes del derecho e, implícitamente, a las diferencias que nuestro sistema jurídico tendría con los que reconocen a los precedentes fuerza vinculante, para oponerse a la obligación de los tribunales inferiores a seguir los precedentes del máximo tribunal. En 
Sin embargo, el caso es que hace ya unos cuantos años asistimos a una paulatina pero sostenida evolución de jurisdicciones como la alemana ${ }^{8}$ y la española ${ }^{9}$ hacia un reconocimiento de fuerza vinculante a los precedentes en materia penal, mientras que, en diversos países que siguen el common law, los tribunales, por lo menos en los niveles más altos de la pirámide jurisdiccional, se comportan con mayor libertad frente al precedente de lo que se supone corresponde a estos sistemas ${ }^{10} \mathrm{y}$, por otra parte, prestan mayor atención al principio de legalidad penal y a los intereses que éste está destinado a proteger. ${ }^{11}$

efecto, el Pleno de la Corte Suprema rechazó, en varias resoluciones de fecha 19 de julio de 2002, reconocer a las decisiones de su Sala Penal un efecto vinculante, aun cuando éstas habían sido pronunciadas en el contexto de un recurso de nulidad destinado a unificar la doctrina, y ello con el fundamento de que (como lo sostiene el Código Civil) "sólo corresponde al legislador explicar o interpretar la ley de un modo generalmente imperativo, y las sentencias judiciales no tienen fuerza obligatoria sino respecto de las causas en que actualmente se pronunciaren; y este precepto -de carácter general- no se encuentra modificado... Por lo demás, el referido principio representa una garantía de la independencia de los jueces". Esta decisión está disponible en Boletín de Jurisprudencia del Ministerio Público, $\mathrm{N}^{\circ}$ 12, septiembre de 2002, pp. 120-121, consultado en http://dspace.utalca.cl/retrieve/447/Bolet\%3Fn_12.pdf.

${ }^{8}$ Así, según lo establecido por el Tribunal Federal (BGH) alemán, respecto de aquellas cuestiones en las cuales el propio BGH haya fijado doctrina a través de una "jurisprudencia constante" (ständige Rechtsprechung), los tribunales inferiores a él sólo pueden desviarse de la misma si "razones claramente preponderantes o incluso absolutamente imperiosas juegan a favor de ello" (BGH, citado por Alexy, R. I Dreier, R. "Precedent in the Federal Republic of Germany", en MacCormick / Summers (Eds.), en Interpreting Precedents. A comparative Study, Aldershot-Brookfield-Singapore-Sydney: Ashgate/Dartmouth, 1997, p. 30). Además, la "vinculación vertical" de la jurisprudencia de los tribunales superiores adquiere eficacia práctica en Alemania, por lo menos a través de la obligación de todo tribunal superior que se haya apartado del precedente de un tribunal de mayor jerarquía, de conceder (declarar admisible) el recurso que sea presentado por las partes para ante este último (Alexy y Dreier, op. cit., p. 32), obligación que en materia penal se vuelve aún más enérgica, pues exige activamente del tribunal que se aparte del precedente presentar de propia iniciativa el asunto ante el tribunal superior (Ibíd., p. 38), sin necesidad de esperar que la parte agraviada recurra (véase. Couso, op. cit., p. 17).

${ }^{9}$ Especialmente significativo parece el paso en esa dirección que se daría en España de aprobarse la reforma al recurso de casación para la unificación de doctrina (en materia penal), impulsada por el gobierno español, que reconoce abiertamente fuerza vinculante a los precedentes del Tribunal Supremo, al proponer como un fundamento del recurso la "contradicción de la sentencia con la jurisprudencia del Tribunal Supremo", tal como lo establece la nueva redacción propuesta por el proyecto de ley para el Art. 848 de la Ley de Enjuiciamiento Criminal. Para la discusión sobre el tema en Chile, este cambio es de alto interés, considerando que la retórica contraria al uso de precedentes en materia penal en nuestro país, en buena medida reproduce alguno de los argumentos con que, históricamente, se resistió la vinculación al precedente, como, por ejemplo, el que ve en esa práctica una lesión a la independencia judicial.

${ }^{10}$ En el Reino Unido, desde 1966 la Cámara de los Lores relajó su doctrina del estricto apego a sus propios precedentes, anunciando que se apartaría de ellos en casos apropiados, si bien desde entonces ha revocado explícitamente sus precedentes a razón de menos de una vez por año; véase Bankowski et al., "Precedents in the United Kingdom" en MacCormick / Summers (Eds.), Interpreting Precedents. A comparative Study, Aldershot-Brookfield-Singapore-Sydney: Ashgate/Dartmouth, 1997). La Corte Suprema Federal de los Estados Unidos también mantiene un innegable espacio para apartarse de sus propios precedentes, como lo demuestran los estudios basado en el attitudinal model (Couso, op. cit., pp. 21-22). Por su parte, en materia de "vinculación vertical", la fundamental práctica del distinguishing ofrece a los tribunales inferiores más espacio para decidir cuándo aplicar los precedentes del que podría pensarse (Couso, op. cit., pp. 14 y 18-19).

${ }^{11}$ Véase Couso, op. cit., pp. 39-42 (sobre los principios nullum crimen sinne lege y de "protección de confianza") y 28-29 (sobre el principio de separación de poderes). 


\section{2. ¿Qué es un precedente y qué significa seguir un precedente?}

Prescindiendo por ahora de las diferencias entre los diversos sistemas jurídicos, puede entenderse por precedentes a "decisiones previas que funcionan como modelos para decisiones futuras". ${ }^{12}$ Este servir de "modelo" puede reducirse, como se verá, a una función de ilustración de soluciones posibles, o puede alcanzar diversos grados de fuerza vinculante.

En los sistemas jurídicos del common law, estrictamente hablando, el precedente será sólo aquella decisión previa que sea vinculante y, de hecho, sólo aquella parte de esa decisión previa que efectivamente vincula en el caso presente, ${ }^{13}$ usualmente denominada ratio decidendi o bolding. Dicho de otra forma, en sentido amplio es precedente una decisión judicial previa que por su semejanza con el caso actual "viene al caso", es decir, debe ser tenida en cuenta en el razonamiento judicial (en una perspectiva ex ante, podría decirse), justamente para examinar si contiene un "precedente" en sentido estricto, lo que sólo se sabrá ex post, una vez que el tribunal identifique en aquella decisión una ratio aplicable al caso actual, habida cuenta de la analogía entre los hechos relevantes.

MacCormick y Summers identifican 4 tipos básicos de "estatus" de los precedentes desde el punto de vista de su fuerza vinculante, con diversos matices al interior de algunos de esos tipos básicos. ${ }^{14}$

$1^{\circ} \quad$ Vinculación formal: caso en el cual "una decisión que no respete el efecto vinculante de un precedente es ilegal y, por ello, está sujeta a revocación por la vía de un recurso". 15,16

$2^{\circ}$ Sin vinculación formal, pero tiene fuerza: en este caso "una decisión que no respete la fuerza del precedente, si bien es legal, puede ser objeto de críticas por esta razón, y puede ser por ello revocada", ${ }^{17}$ como es el caso de la vinculación que ejerce la "jurisprudencia constante" (ständige Rechtsprechung) del Tribunal Federal

${ }^{12}$ MacCormick y Summers, op. cit., p. 1.

${ }^{13}$ Bankowski et al., op. cit., p. 323.

${ }^{14}$ Op. cit., pp. 554 y ss., donde pueden consultarse matices que en este lugar no es necesario reproducir.

${ }^{15}$ Ibid., p. 554.

${ }^{16}$ Como ocurre con la vinculación de los tribunales del Reino Unido respeto de los precedentes emanados de los tribunales superiores, que son un caso de vinculación formal "estricta” (no admitiría excepciones); véase Bankowski et al., op. cit., p. 325. También producen vinculación formal los fallos de la Corte de Apelaciones de Inglaterra y Gales respecto de ella misma, y constituyen un caso de vinculación formal "vencible", que sí admite excepciones: este tribunal debe seguir sus propios precedentes, salvo en dos casos excepcionales: cuando uno de sus precedentes fue implícitamente revocado por una decisión posterior de la Cámara de los Lores, y cuando uno de sus precedentes se emitió "per incuriam”, esto es, en la ignorancia de la legislación (statute) o de un precedente vinculante relevante; véase Bankowski et al., op. cit., p. 326.

${ }^{17}$ MacCormick y Summers, op. cit., pp. 554-555. 
(BGH) alemán, de la cual los tribunales inferiores a él sólo pueden desviarse, según lo sostiene el propio $\mathrm{BGH}$, si "razones claramente preponderantes o incluso absolutamente imperiosas juegan a favor de ello". ${ }^{18,} 19$

$3^{\circ}$ Sin vinculación formal y no tiene fuerza (en el sentido del $\mathrm{N}^{\circ} 2^{\circ}$ ), pero ofrece un apoyo adicional: en cuyo caso "una decisión sin este (apoyo) es legal y puede estar justificada, pero no tan bien justificada como lo estaría si se hubiese invocado el precedente, por ejemplo, para demostrar que la decisión que se adopta está en armonía con el precedente" $20,21$.

$4^{\circ} \quad$ Mero valor ilustrativo o de otro tipo: Un ejemplo de este valor ilustrativo se da en el recurso, por parte de los (litigantes y) tribunales del Reino Unido, a los precedentes de los tribunales de Estados Unidos y de otros países europeos. ${ }^{22}$

\section{3. ¿Vinculación de iure vs vinculación de facto?: carácter normativo de toda práctica de seguimiento de precedentes}

Al comparar el valor que se asigna a los precedentes, sobre todo de los tribunales superiores, en los países del common law vis-à-vis los sistemas jurídicos continentales tradicionalmente se ha sostenido que la primera da cuenta de una vinculación de iure

\footnotetext{
${ }^{18} \mathrm{BGH}$, citado por Alexy y Dreier, op. cit., p. 30.
}

${ }^{19}$ Otro caso de interés, es el de la jurisprudencia del Tribunal Supremo español, primero en materia civil, cuyo desconocimiento (si es doctrina reiterada en a lo menos dos fallos) es fundamento para la interposición de un recurso de casación por infracción de la (ley o la) "doctrina”, y más tarde en materias sociales y algunas materias penales (las relativas a la Ley orgánica reguladora de la responsabilidad penal de los menores y al Derecho penitenciario), en las que se ha establecido el "recurso de casación para unificación de doctrina", para resolver casos de disparidad de doctrina entre los tribunales superiores de diversas Autonomías, por medio de resoluciones del Tribunal Supremo español que, en el futuro, de no seguirse, sirven de fundamento suficiente para casar cualquier otro fallo que se les aparte, lo que realmente se acerca al primer grado de vinculación -“vinculación formal"-; véase Ruiz Miguel, A. / Laporta, F. J., "Precedents in Spain”, en MacCormick / Summers (Eds.), Interpreting Precedents. A comparative Study, Aldershot-Brookfield-SingaporeSydney: Ashgate/Dartmouth, 1997, p. 274. Además, de aprobarse la reforma enviada por el gobierno al Congreso de los Diputados, este recurso se extenderá a las materias penales con el objeto de contribuir a fijar doctrinas en materia penal, vinculantes para los demás tribunales del Estado, por medio de precedentes que caben dentro de esta categoría; véase Couso, op. cit., p. 5 y nota al pie 7.

${ }^{20}$ MacCormick y Summers, op. cit., p. 555.

${ }^{21}$ De acuerdo con Alexy y Dreier (op. cit., p. 29), podría constituir un caso de este tipo de (no) vinculación el peso que el Tribunal Constitucional Federal alemán (BVerfG) asigna a los precedentes del Tribunal Federal alemán $(\mathrm{BGH})$, pues "su pretensión de validez más allá del caso singular se basa sólo en la fuerza de convicción de sus razones (Überzeugungskraft ibrer Gründe) y en la autoridad y competencia del tribunal" (BVerfG, citado por Alexy y Dreier, Ibidem), posición que, como se vio, contrasta con la sostenida por el propio $\mathrm{BGH}$, que asigna una mayor fuerza vinculante a sus propios precedentes. Con todo, la concepción que el BVerfG tiene sobre el valor de los precedentes del BGH parece privarles de una característica que -como se verá más abajo- parece ser constitutiva del concepto de precedente: su validez como razón justificatoria de la nueva decisión, con relativa independencia de su contenido; por ello, incluso puede dudarse de la pertinencia de clasificarlos bajo esta tercera categoría.

${ }^{22}$ Bankowski et al., op. cit., p. 327. 
del tribunal al precedente, esto es, se trata de una práctica que responde a un deber jurídicamente impuesto (deber cuya fuente son a su vez otros precedentes), mientras que la segunda, en cambio, no da cuenta de vinculación jurídica alguna, sino que sólo una "vinculación de facto" que, técnicamente hablando, no sería una verdadera forma de "vinculación”, sino apenas una regularidad. ${ }^{23}$

Esta diferencia se expresaría jurídicamente en que en los países del common law los precedentes son una fuente del Derecho, que obligan con independencia de la calidad de las razones que los sustentan, mientras que en los sistemas jurídicos continentales no son una fuente del derecho, de modo que los tribunales no se encuentran obligados a seguirlos, sino que simplemente los siguen cuando hay buenas razones para ello. Sin embargo, como lo ha destacado Peczenik, y dejando de lado los casos ya enunciados (cada vez más frecuentes) de vinculación formal o de iure al precedente existentes en los sistemas jurídicos continentales (especialmente respecto de los precedentes de los tribunales constitucionales ${ }^{24}$ ), la práctica de seguimiento de facto de los precedentes, siempre tiene un carácter normativo, ${ }^{25}$ luego, no es únicamente "de facto". Los tribunales de estos sistemas jurídicos no siguen precedentes simplemente porque son un modelo de decisión disponible como cualquier otro, sino que los emplean (y los citan) de forma "justificatoria”, es decir apoyando su decisión en el precedente como una razón -entre otras- que justifica la decisión. ${ }^{26}$

Al actuar así, estos tribunales generalmente convierten al precedente (incluso a aquél que supuestamente vincula sólo de facto) en una razón en apoyo de la decisión con relativa independencia de la corrección de su contenido, es decir, el precedente es una razón que apoya la decisión o sentencia del tribunal que lo sigue, no únicamente por la calidad de sus fundamentos - "tenía razón la Corte Suprema cuando dijo tal cosa"- (lo que apela a razones "sustantivas"), sino por el hecho de ser un precedente -porque "esto ya fue decidido de este modo por la Corte Suprema" - (una razón "formal”). ${ }^{27,28}$

\footnotetext{
${ }^{23}$ Peczenik, A., "The Binding Force of Precedents", en MacCormick / Summers (Eds.), Interpreting Precedents. A comparative Study, Aldershot-Brookfield-Singapore-Sydney: Ashgate/Dartmouth, p. 465.

${ }^{24}$ Véase Couso, op. cit., p. 4.

25 Peczenik, op. cit., p. 465.

${ }^{26}$ Ibid., pp. 465-466.

${ }^{27}$ Naturalmente, esta razón formal que aporta el precedente a la nueva decisión se basa a su vez en diversas razones sustantivas, que son razones a favor de la práctica de seguir precedentes (necesidad de garantizar seguridad jurídica, predictibilidad de las decisiones de los tribunales y un igual tratamiento jurídico a los ciudadanos); véase Couso, op. cit., pp. 19 y ss.

${ }^{28} \mathrm{Si}$ bien lógicamente puede distinguirse entre el carácter normativo de la práctica de seguimiento de precedentes y la naturaleza del precedente como razón formal, pues los tribunales pueden usar en forma justificatoria un precedente simplemente porque encuentran "convincentes" las razones invocadas por el fallo anterior (razones sustantivas) y no porque "es correcto" seguir los precedentes (razón formal), el interés -también apreciable en la generalidad de los casos en que los tribunales continentales citan expresamente un precedente- por invocar en apoyo de su decisión precisamente al "vehículo" portador de esas razones -una sentencia anterior, típicamente de un tribunal superior- sugiere con fuerza que el precedente empleado en forma justificatoria, por regla general, opera a lo menos parcialmente como una razón formal a favor de la
} 


\section{4. ¿Qué es lo que se sigue cuando se sigue un precedente?}

En los tribunales de países del common law, cuando se reconoce a un precedente un efecto formalmente vinculante, ese efecto se predica de una parte de la decisión previa dictada en un caso análogo. Esa parte vinculante se denomina ratio decidendi en el Reino Unido, ${ }^{29}$ y holding (postura o determinación adoptada) en algunas jurisdicciones de Estados Unidos, ${ }^{30}$ o a veces simplemente rule (regla), ${ }^{31}$ y puede ser definida como “cualquier regla jurídica a la que un juez ha tratado expresa o tácitamente como un paso necesario para llegar a su conclusión, teniendo en cuenta la línea de razonamiento que ha seguido, o como una parte necesaria de sus instrucciones al jurado". ${ }^{32}$

Se trata, en todo caso, de una regla que, para ser enunciada y comprendida, mantiene una cierta relación con los hechos para los cuales fue formulada. ${ }^{33}$ La ratio decidendi se extrae de y se formula mediante una asociación entre lo decidido y los hechos relevantes del caso a los que se aplica esa decisión. ${ }^{34}$

Así definida la ratio -que es el precedente en "sentido estricto"-, su aplicación exige que el caso presente sea análogo al anterior precisamente en relación con los hechos relevantes a los que se aplicó la decisión ${ }^{35}$ o, dicho de otra manera, exige calificar los hechos del caso actual en el sentido de si acaso pueden ser considerados como hechos del tipo cubierto por la ratio del precedente. ${ }^{36}$ La decisión de qué semejanzas son relevantes y cuáles no, se basa en reglas y en razones justificatorias (rationales) de estas reglas, que invocan razones de justicia o de utilidad social. ${ }^{37}$

decisión del tribunal que lo cita; con ello, sin decirlo, este tribunal se comporta sugiriendo que es correcto, o al menos preferible, seguir los precedentes.

${ }^{29}$ Bankowski et al., op. cit., pp. 323, 336.

${ }^{30}$ Summers, op. cit., p. 383.

${ }^{31}$ Kaplan, J. / Weisberg, R. / Binder, G., Criminal Law. Cases and Materials, New York: Aspen, 2000, p. 13 (en adelante, cit. Kaplan et al.).

32 Bankowski et al., op. cit., p. 338.

33 Marshall, G., "What is Binding in a Precedent", en MacCormick / Summers (Eds.), Interpreting Precedents. A comparative Study, Aldershot-Brookfield-Singapore-Sydney: Ashgate/Dartmouth, 1997, p. 506.

${ }^{34}$ Ibid., p. 505.

${ }^{35}$ Véase Kaplan et al., op. cit., p. 13 y Peczenik, op. cit., p. 474.

${ }^{36}$ Bankowski et al., op. cit. p. 337.

${ }^{37}$ Kaplan et al., op. cit., p. 13, quienes ofrecen el siguiente ejemplo para ilustrar la "semejanza en lo relevante" y el rol de las rationales para decidir qué hechos son relevantes para buscar la semejanza:

"Un oficial de policía (Duke) mata de un disparo a un ladrón que va huyendo. ¿Incurre el policía en el delito de homicidio -doloso o imprudente-? ...Supongamos que en un caso anterior, el oficial Wayne infructuosamente intentó que el jurado fuera instruido en el sentido de que un oficial de policía no era culpable (de homicidio) bajo la ley, si intentaba con ello impedir la huida de un peatón imprudente (lo que constituye una "falta" o "contravención”). Hasta que no sepamos más acerca de por qué el juez rechazó la instrucción solicitada no podemos decir si el caso anterior tiene una semejanza relevante con el caso de Duke. Supóngase que el juez del caso Wayne rechazó la instrucción solicitada porque la ley no mencionaba explícitamente ninguna defensa como esa. Aparentemente Duke está en la misma situación; la instrucción que solicita será entonces prohibida por una regla (la ratio o bolding, establecida por el precedente -caso Wayne-) que excluye las defensas no contempladas en la ley. El caso de Duke tiene entonces una seme- 
Sólo con esa semejanza en lo relevante será correcto (y obligado) aplicar el precedente al caso actual. Pues de tal forma ambos casos versan sobre el mismo "asunto" (issue). ${ }^{38}$

En los tribunales de los países del common law, las demás "razones” empleadas en la decisión precedente, que no califican como ratio decidendi, serán consideradas dicta u obiter dicta, ${ }^{39}$ y pueden tener cierta fuerza, pero no el efecto vinculante asignado a aquella. ${ }^{40}$

La distinción entre ratio decidendi y dictum en esos países es importante, ya que la consecuencia de calificar a un elemento como ratio decidendi es que el tribunal no podrá apartarse del precedente, ni aun cuando le asistan razones de peso para preferir hacerlo. Esa decisiva consecuencia de la identificación de un elemento que puede jugar como ratio incide en el desarrollo de una práctica de "distinción" (distinguishing) entre el caso precedente y el actual bastante sofisticada, cuando no excesiva, por parte de litigantes y, en su caso, del tribunal, así como de "explicaciones" de la "verdadera doctrina" del caso precedente (que reducen el alcance de la ratio o holding), de manera de evitar el empleo de precedentes que no se quiere aplicar al caso presente. ${ }^{41}$

\section{Algunos factores institucionales que influyen en la práctica de seguimiento de precedentes}

¿Qué condiciones hacen posible, en los diversos ordenamientos jurídicos, un mayor grado de apego a los precedentes y de uniformación de la jurisprudencia?

En el plano normativo, por cierto una condición que favorece esos efectos es la obligación estricta de seguir los precedentes, de tal modo que la resolución que se aparte del precedente puede ser recurrida y será revocada por ese solo motivo.

janza relevante con el caso de Wayne. Pero supóngase que el juez del caso Wayne rechazó la instrucción solicitada en razón de que (y éste será entonces el holding) impedir la huida de un sospechoso de una falta (misdemeanor) no justifica una muerte. Si el robo es un delito (felony), la solicitud de Duke no está cubierta por la regla del caso Wayne. Entonces surge la pregunta de si la muerte causada por Duke está cubierta por la razón justificatoria (rationale) del caso anterior, es decir, si acaso impedir la huida del autor de un robo es un propósito suficientemente valioso para justificar matarlo. Si no lo es, entonces el robo es semejante en lo relevante a la imprudencia peatonal, incluso si uno es un delito y el otro una falta" (op. cit., p. 13, la traducción es mía y, para una mejor comprensión, se refiere a "ladrón” y a "robo" cuando el original aludía a "burglar" y "burglary").

${ }^{38}$ Summers, op. cit., p. 383.

${ }^{39}$ Bankowski et al., p. 337, quien explica que esas otras razones pueden consistir en principios jurídicos, argumentos de política pública, observaciones sobre valores fundamentales, análisis de situaciones fácticas, y cualquier formulación de una regla o decisión en un punto de derecho, todas las cuales pueden ser citadas por la decisión posterior y "manifiestamente añadirle peso a un argumento a favor o en contra de una determinada decisión".

${ }^{40}$ No tienen fuerza vinculante porque el tribunal que emitió la decisión precedente normalmente no ha prestado a los obiter dicta la cuidada atención que debe haber prestado a los holding, ni ha tenido suficiente información respecto de aquellos porque las partes por lo general se concentran, en sus alegatos, en el asunto sobre el cual realmente discurre el caso (véase Summers, op. cit., p. 385).

${ }^{41}$ Bankowski et al., pp. 342, 333. 
Ahora bien, el caso es que, con o sin obligación estricta de seguir los precedentes, una serie de variables institucionales y relativas a la cultura judicial, pueden favorecer o dificultar la generación de una jurisprudencia más uniforme y cierta a nivel de las cortes supremas, y reconocida y aplicada por las cortes de apelaciones y los tribunales inferiores.

A. A nivel de la Corte Suprema ("uniformación interna”), pueden identificarse las siguientes variables.

$1^{\circ} \mathrm{Si}$ acaso la Corte tiene una "orientación prospectiva" o una "retrospectiva". 42 La primera determina que la decisión de un caso pueda convertirse en un precedente, y requiere que la Corte Suprema, al resolverlo, "mire hacia el futuro, hacia los próximos casos que se refieran a asuntos idénticos o similares, y tenga la intención de guiar o determinar su decisión”. ${ }^{43}$ En cambio, la "orientación retrospectiva” está presente "cuando una Corte concentra su atención sólo o principalmente en la resolución del asunto específico planteado en el concreto caso singular"; ${ }^{44}$ más típicamente, esta "actitud retrospectiva es típica de cortes supremas que entienden su función como la de una tercera instancia en el caso singular", que interpretan, por tanto, las reglas legales "con el propósito de establecer un criterio de decisión del caso específico, más que con el propósito de extraer un estándar que pudiera ser válido también para la adopción de decisiones en el futuro". 45

$2^{\circ}$ Directamente relacionada con aquella variable se encuentra la posibilidad de la Corte Suprema de seleccionar los casos que conocerá, lo que precisamente favorece una orientación prospectiva; en cambio, la orientación retrospectiva se da generalmente en cortes que no pueden seleccionar los casos que conocerán, sino que deben decidir todos los casos que se les presentan por las partes. ${ }^{46}$ En cualquier caso, más que ordenarse en torno a dos extremos (con o sin capacidad de seleccionar a su arbitrio), los sistemas jurídicos se ubican en un continuo de diversos grados de discrecionalidad para hacer la selección, desde el poder de la Corte Suprema de Estados Unidos para escoger apenas algunas decenas o cientos de casos al año on certiorari hasta escenarios como el que se da con la obligación de la Corte Suprema de Italia, ante la cual cualquier parte tendría un derecho constitucional a elevar su asunto, pasando por numerosas cortes que disponen de variables grados de poder seleccionar casos, como el Tribunal Federal Alemán (BGH), que decidiría su competencia de acuerdo con la "importancia del asunto jurídico invo-

${ }^{42}$ Taruffo, M., "Institutional Factors Influencing Precedents”, en MacCormick / Summers (Eds.), Interpreting Precedents. A comparative Study, Aldershot-Brookfield-Singapore-Sydney: Ashgate/Dartmouth, 1997, p. 444.
${ }^{43}$ Ibidem.
${ }^{44}$ Ibid. p. 445.
45 Ibidem.
${ }^{46}$ Ibidem. 
lucrado" en la causa. ${ }^{47}$ En ese continuo, a mayor capacidad para decidir libremente los casos que conocerá, mayor orientación prospectiva parece tener el tribunal, concentrándose en los casos que más significativos parecen para definir reglas jurídicas relevantes para el futuro.

$3^{\circ}$ Otra variable mencionada por Taruffo es la organización del tribunal, en términos de su tamaño y composición. ${ }^{48}$ Sobre todo si se relaciona con un poder amplio para seleccionar los asuntos que conocerá, las cortes supremas compactas y pequeñas, en las que sus miembros son estables en el tiempo, ${ }^{49}$ y precisamente por ser pocos y permanecer largo tiempo adquieren alta visibilidad pública (el paradigma serían los nueve miembros de la Corte Suprema de los Estados Unidos de América), son las que tienden a ofrecer mayor consistencia y permanencia a la jurisprudencia que producen, que, de alguna manera es reconducible a una "fuente" muy unificada: ese compacto y estable grupo de personas. ${ }^{50}$ Las cortes supremas que, en cambio, cuentan con muchos jueces, paneles, salas y secciones, lo que es inevitable cuando su obligación de conocer muchos asuntos les impone una enorme carga de trabajo, deben adoptar algunos mecanismos especiales para evitar la natural dispersión que tiende a producirse en la forma de decidir los casos similares.

$4^{\circ}$ Precisamente en las cortes supremas en las que cuentan con muchos jueces, paneles, salas y secciones, una variable que favorece la uniformación de la jurisprudencia, es la adopción de mecanismos que racionalicen y en cierto modo "centralicen" la práctica de apartarse del precedente o de revocarlo o modificarlo. Tal es el caso de la obligación de someter al "pleno" (denominada en Alemania, "obligación de presentar" o Vorlagepflicht) la decisión de apartarse del precedente o de revocarlo o modificarlo, ${ }^{51}$ así como de la práctica (surgida por iniciativa de los jueces, y no de la ley) del Tribunal Supremo español, cuya Sala Penal (compuesta de Secciones, como el BGH alemán) celebra, desde 1997, unas Juntas Generales destinadas a unificar criterios jurisprudenciales en torno a cuestiones que surjan sobre interpretación de alguna ley penal nueva o en

\footnotetext{
${ }^{47}$ Ibid., p. 444.

48 Ibid., p. 446.
}

${ }^{49} \mathrm{La}$ permanencia de sus miembros en el tiempo es con mayor razón importante si se tiene en cuenta que, de acuerdo con los estudios empíricos sobre seguimiento de precedentes en la Corte Suprema de los EE.UU., en las materias más "salientes" predomina en sus jueces una actitud "preferencial" (seguimiento de las propias preferencias al fallar ese tipo de casos) antes que una "precedencial” (seguimiento de precedentes); véase Spaeth, H. / Segal, J. Majority Rule or Minority Will. Adherence to Precedents on the U.S. Supreme Court, Cambridge University Press, 1999, pp. 308 y ss., y la aplicación de su marco analítico al caso de la Corte Suprema chilena, por Couso y Mera, op. cit., passim.

${ }^{50}$ Ibid., p. 447.

${ }^{51}$ Así lo hace actualmente en el Reino Unido la Cámara de los Lores (véase Bankowski et al., op. cit., p. 343) y, en Alemania, el Tribunal Constitucional Federal (BverfG) y el Tribunal Federal (BGH), ya sea que una de sus "salas" (la penal) se quiera apartar del precedente de otra sala (la civil), ya que una de las secciones o paneles de una determinada sala (por ejemplo, el segundo panel de la Sala Penal) se quiera apartar del precedente de otra de las secciones de esa misma sala (por ejemplo, el cuarto panel de la Sala Penal) (véase Alexy y Dreier, op. cit., pp. 31-32). Procedimientos similares se aplican en niveles más bajos de la jurisdicción alemana. 
torno a cuestiones que hayan sido resueltas con diverso criterio por distintas secciones, pudiéndose suscitar tales cuestiones con ocasión de un recurso de casación planteado ante una de esas secciones, cuya resolución se podrá suspender mientras la Junta General defina una doctrina común. ${ }^{52}$

B. A nivel de las cortes de apelaciones y de los tribunales inferiores (uniformación vertical), el grado de apego a los precedentes de la Corte Suprema se asocia a las siguientes variables:

$1^{\circ}$ Los mecanismos institucionales destinados a promover en los tribunales apego a los precedentes de los tribunales superiores (particularmente, de la Corte Suprema), relacionados con las motivaciones que los tribunales inferiores tengan para ser congruentes con ellos. Así, como lo explica el modelo de la relación "mandante-agente", 53 en el extremo es posible imaginar que si el mandante cuenta con la posibilidad de determinar que se ponga término a la relación (destitución de los jueces del tribunal inferior), podría esperarse una alta motivación del "agente" para manifestar congruencia y receptividad. ${ }^{54}$ Pero, lejos de ese extremo -reñido con la imagen de un juez independiente, propia de un Estado de Derecho-, también puede esperarse una motivación significativa por parte del "agente" si una consecuencia más o menos cierta de su falta de congruencia con el precedente será la nulidad (o anulabilidad) del fallo que se aparte de él. De hecho, y contrariamente a los temores que expresan algunos jueces chilenos frente a la posibilidad de que se instaure en Chile un sistema de precedentes, ${ }^{55}$ es ajeno al mismo la existencia de algún mecanismo de sanción disciplinaria para el tribunal que se aparte del precedente del tribunal superior. ${ }^{56}$

${ }^{52}$ El Estatuto de estas definiciones doctrinarias es definido por la propia Sala Penal de la siguiente forma: "aunque no siendo jurídicamente vinculantes, los acuerdos deben ser respetados, en aras del bien que debe prevalecer, que es el de la estabilidad y uniformidad de la doctrina jurisprudencial" (Granados Pérez, C. (Ed.), Acuerdos del Pleno de la Sala Penal del T.S. para unificación de la jurisprudencia. Años 2001-2002, 2a Edición, actualizada y ampliada, Valencia: Tirant Lo Blanch, 2003, pp. 11-12, sintetizando la doctrina de la Sala Penal en la materia, en un libro que recoge las doctrinas penales unificadas por medio de este procedimiento).

${ }^{53}$ Modelo destinado a explicar los factores que determinan, en los tribunales inferiores, la mayor o menor congruencia que ellos guardan con la jurisprudencia de la Corte Suprema y su mayor o menor receptividad a los cambios que ella experimente en el tiempo; véase Songer, D. / Segal, J. / Cameron, C. "The Hierarchy of Justice: Testing a Principal-Agent Model of Supreme Court - Circuit Court Interactions", en American Journal of Political Science, Vol. 38, $\mathrm{N}^{\circ} 3$ (agosto de 1994), pp. 673-696 (en adelante, cit. Songer et al.). Este modelo es aplicado por Couso y Mera, op. cit., para explicar el nivel de apego de las cortes de apelaciones (y cortes marciales) chilenas a los precedentes de la Corte Suprema.

${ }^{54}$ Véase lo recién señalado sobre este modelo en la anterior nota.

${ }^{55}$ Como se constató en el Taller de Discusión con ministros de cortes de apelaciones y abogados realizado en el marco de la investigación que dio origen a este trabajo (véase supra, nota al pie 4).

${ }^{56}$ El ejemplo que se ofrece más abajo, del Tribunal Superior Administrativo de Renania del NorteWestfalia que, sólo tras sufrir 160 veces la revocación, por parte del Tribunal Federal Administrativo, de sus fallos "incongruentes" con la jurisprudencia de éste, decidió adherirse a la misma, da cuenta clara de que la única consecuencia que debiera enfrentar un tribunal que se aparta de un precedente con fuerza vinculante 
Otro mecanismo institucional para promover la uniformación vertical de la jurisprudencia, y que se emplea en Alemania, aun a falta de una doctrina de vinculación estricta al precedente, es la obligación -a la que ya se aludió- de todo tribunal superior que se haya apartado del precedente de un tribunal de mayor jerarquía, de conceder el recurso que sea presentado por las partes para ante este último, obligación que en materia penal se vuelve aún más enérgica, pues exige activamente del tribunal que se aparte del precedente presentar de propia iniciativa el asunto ante el tribunal superior, sin necesidad de esperar que la parte agraviada recurra. ${ }^{57}$

$2^{\circ} \mathrm{El}$ papel de los abogados. En los sistemas que exigen a los tribunales inferiores apego estricto a los precedentes del tribunal superior, las complejidades que puede involucrar la identificación de un caso de desconocimiento del precedente estrictamente vinculante quedan entregadas al papel de los abogados de la parte perjudicada con el fallo que incurre en ese vicio. ${ }^{58}$ Pero también respecto de los precedentes cuya fuerza vinculante es "superable" por el peso de razones cualificadas, el sistema de recursos y el trabajo de los abogados litigantes en su utilización pueden desempeñar un rol importante, como guardianes del valor y peso del precedente. ${ }^{59}$ En ambos casos, si la revocación de la decisión "incongruente" con la jurisprudencia del tribunal superior es una consecuencia más o menos cierta, en el marco de un "sistema de monitoreo" 60 que funciona bien, la ineficacia del propio comportamiento "preferencial" se convertirá más temprano que tarde en un desincentivo poderoso para los jueces de los tribunales inferiores, que no querrán repetir muchas veces el esfuerzo de construir y redactar una decisión disidente ("incongruente" con la jurisprudencia del tribunal superior) que nunca termina decidiendo el asunto, pues siempre es revocada. ${ }^{61}$

$3^{\circ}$ Asociados a este rol de los abogados se encuentran otros factores que determinan la calidad del "sistema de monitoreo" de la relación "mandante-agente", a saber, el conocimiento que los abogados tengan de la jurisprudencia de los tribunales superiores

es la revocación (en su caso, reiterada, y por ello, acaso, "desmoralizadora") de su fallo "por el sólo hecho de apartarse del precedente": en eso consiste un precedente vinculante, y no en que se sancione personalmente a los jueces que se apartaron de él.

${ }^{57}$ Véase Alexy y Dreier, op. cit., pp. 32, 38.

58 En estudios empíricos sobre el grado de "vinculación vertical” de los precedentes de la Corte Suprema de los EE.UU., se ha destacado el rol de "alarma de fuego" que los abogados, a través de los recursos judiciales, pueden desempeñar respecto de la tendencia de los tribunales inferiores a apartarse del precedente; véase Songer et al., p. 693.

${ }^{59}$ Es interesante señalar que el Tribunal Federal alemán ha declarado la responsabilidad del abogado por perjuicios ocasionados a su cliente por negligente omisión de alegar precedentes de los tribunales superiores favorables a su representado; véase Alexy y Dreier, op. cit., p. 31.

${ }^{60}$ Songer et al., op. cit., p. 693.

${ }^{61}$ Es interesante el caso referido por Alexy y Dreier, op. cit., p. 37, del Tribunal Superior Administrativo de Renania del Norte-Westfalia que, sólo tras sufrir 160 veces la revocación, por parte del Tribunal Federal Administrativo, de sus fallos "incongruentes" en relación con una determinada tesis jurisprudencial sustentada por el primero, accedió a abandonar su propia tesis, con una fundamentación que, junto con aludir razones "precedenciales" (importancia de la uniformidad en la jurisprudencia, como valor), da cuenta de una cierta resignación ante la ineficacia de su actitud preferencial o "incongruente". 
y la posibilidad real que aquellos tengan de reclamar ante el tribunal superior -lo que es función de la forma como se configura el sistema de recursos procesales- frente a la falta de "congruencia" o de "receptividad" de los tribunales inferiores en relación con la jurisprudencia del tribunal superior. En particular, respecto del primero, son importantes las prácticas destinadas a publicar las decisiones de las cortes supremas, pues "una decisión en realidad sólo puede convertirse en precedente si es conocida, no sólo por las partes del caso singular, sino también por otros tribunales, los abogados y el público general". ${ }^{62}$ Estas prácticas forman parte del contexto institucional que hace posible un sistema de precedentes, con independencia de que sean desarrolladas por la institución pública que los produce (los propios tribunales) o, de forma más o menos sistemática, por diversas agencias y operadores privados (periódicos, revistas, bases de datos electrónicas) del sistema de justicia respectivo. Con todo, una condición previa para que las ratione de los precedentes adquieran visibilidad es la calidad de la fundamentación de los fallos que los contienen, siendo fundamental, entonces, la existencia de una práctica satisfactoria, a nivel de los tribunales superiores, de fundamentación de los fallos. ${ }^{63}$

\section{II. ¿Por Qué la Sala Penal no ha logrado uniformar la jurisprudencia COMO SE ESPERABA DE ELLA?}

La explicación de este relativo fracaso se encuentra precisamente en la falta de -o la debilidad con que se presentan- las condiciones que se acaba de exponer, que favorecen el apego a los precedentes y, con ello, la uniformación "interna" y "vertical" de la jurisprudencia.

\section{Orientación prospectiva y vocación de fijar doctrinas estables en el tiempo}

La Corte Suprema, y su Sala Penal en particular, no han adoptado una perspectiva de tribunal de casación, orientado a establecer doctrinas jurídicas estables en el tiempo. Las razones son culturales y de diseño institucional.

Una primera razón cultural es la vocación de buscar la "justicia material” en el caso concreto. Las entrevistas a ministros de corte y abogados penalistas dan cuenta de esta realidad, que se traduce en dos actitudes que dificultaron la labor de uniformación de la jurisprudencia asignada a la Sala Penal, especialmente antes de la entrada en vigencia de la reforma procesal penal: primero, una pretensión de revisar la decisión de fondo, más allá de la enmienda de algún error de Derecho específico cometido por la sentencia recurrida, con lo cual la Sala Penal se transforma prácticamente en un tribunal

${ }^{62}$ Taruffo, op. cit., p. 451.

${ }^{63}$ En la investigación de MacCormick y Summers, op. cit., esta variable es una de las que se toman en cuenta al comparar el uso de precedentes en los diversos países analizados. 
de "primera instancia" 64 o desnaturaliza la casación convirtiéndola en una "apelación disfrazada"; ${ }^{65}$ y, segundo, la disposición a abandonar, si es necesario, las tesis que ha sostenido en fallos anteriores, no a través de la afirmación de una tesis nueva -que de ahí en adelante se aplicará consistentemente-, sino mediante la construcción de una interpretación ad-hoc de la ley, por esa sola vez, sobre todo en materia de aplicabilidad de circunstancias atenuantes y agravantes. ${ }^{66}$ La dificultad para renunciar a ese rol de hacer justicia en el caso concreto -renuncia que es una condición para que la Corte Suprema pueda concentrarse en la fijación del Derecho y aplique consistentemente sus tesis-, puede explicarse en parte como una "deformación profesional" de sus ministros, que fueron formados como jueces de instancia, ocupados justamente de dar justicia en el caso concreto. No es de extrañar, entonces, que esta renuncia le resulte más natural a un ministro incorporado al Poder Judicial directamente como juez de la Corte Suprema, quien declaró que:

"Esta es una Corte de Derecho, cuya tarea fundamental es fijar el Derecho; entonces, los problemas de justicia material escapan a nosotros porque son propios de los jueces del fondo... me he dado cuenta con los años que alguien debe cumplir esta función, y me he ido inhibiendo de hacer fallos imbuidos de justicia material”.

Otro ministro de la Corte Suprema, reconociendo su rol como tribunal de casación ("la Corte Suprema no es un tribunal de justicia... es un tribunal de Derecho"), admite, sin embargo que, por razones de equidad, a veces tienen que "torcerle la nariz a la ley". Un tercer ministro de esa Corte afirma derechamente que:

64 "La Sala Penal, salvo excepciones, se comporta como tribunal de primera instancia, preocupada por la justicia material; no tiene pretensión de uniformar jurisprudencia ni de orientar a los tribunales inferiores; en cambio, antes había un cierto afán pedagógico y un intento de fundamentar los fallos, para que los tribunales inferiores encontraran en ellos una orientación jurídica”, opina un prestigioso abogado penalista y profesor de Derecho penal.

65 "Yo me he planteado si la casación es realmente casación o una última instancia; porque uno lee los recursos de casación, y son casi apelaciones disfrazadas y los bien hechos son copia de libros, sin visión personal; yo creo que es una tercera instancia”, opina un Ministro de la Corte de Apelaciones de Santiago.

${ }^{66}$ Según un Ministro de la Corte Suprema entrevistado, pese al amplio acuerdo en dicha Corte en el sentido de que para la atenuante de "irreprochable conducta anterior" basta que el condenado cuente con un extracto de filiación sin condenas anteriores, en casos excepcionales no se concede la atenuante a quien, aún en esa situación, carece de conducta "intachable", si ello conduce a consecuencias indeseadas desde el punto de vista de la "justicia material”, por ejemplo, que "el cabecilla termine mejor (con menor pena) que su coautor"; un Ministro de Corte de Apelaciones de Concepción también reconoce que en ocasiones niega la atenuante (a condenados que cuenten con un extracto de filiación sin condenas anteriores) cuando la pena baja mucho en relación con la gravedad del hecho. En el taller de discusión con Ministros de cortes de apelaciones y abogados también se invocaron las necesidades de flexibilidad para una solución adecuada a la “justicia material” como argumento en contra de una uniformación estricta de la jurisprudencia, en general. Para más detalles, véase en Couso y Mera, op. cit., el análisis de la uniformación interna de la jurisprudencia de la Sala Penal, especialmente en relación con aquella atenuante. 
"el espíritu dentro de la Corte Suprema no es tanto sentar cátedra sobre algunos puntos, sino resolver los casos puntuales con el objetivo de dejar una justicia material en ese caso concreto; eso hace a veces que se incurra en algunas contradicciones... pero normalmente se trata de respetar cierta línea... (si bien) más que hacer doctrina los tribunales tratan de aplicar la justicia material al caso... hay veces en que uno le dobla la mano a la ley cuando no se le ocurre otra cosa para lograr una sentencia justa, uno le ve la cara a los relatores cuando uno le ha dicho blanco y luego le dice gris... (pero) el dolor de la pena lo merece y eso lo hice..."

Pese a ello, varios ministros sostienen que la Sala Penal aspira a mantener consistencia con sus decisiones anteriores. Así, fuera de aquellos casos, los cambios de doctrina son explicados, más que por acomodos ad hoc de la interpretación de la ley, por el hecho de que se produzcan "mayorías ocasionales" partidarias de la tesis contraria, cuando un miembro regular de la Sala ha faltado y esta ha debido ser integrada con un ministro "externo". Como se ve, en cualquier caso, en esta explicación se da cuenta de que la posibilidad de que los jueces de la Sala Penal asuman una actitud "precedencial", 67 es decir, que prefieran fallar de forma consistente con la jurisprudencia de la Sala Penal aun si alguno de ellos tiene una opinión diferente, ni siquiera se plantea, ${ }^{68}$ pese a que las razones de política de justicia favorables a la uniformación de la jurisprudencia no tienen tanto que ver con un deber de consistencia personal del juez con sus fallos anteriores, cuanto con el mejor servicio que se presta al Derecho asegurando una jurisprudencia previsible y que respete el principio de igualdad ante la ley, lo que depende de la consistencia de la Sala Penal con sus fallos anteriores. ${ }^{69}$ Cuando a los jueces chilenos les preocupa la aplicación consistente de las tesis ya establecidas, en general se trata justamente de aquella "autovinculación personal” del juez a sus opiniones pasadas; ${ }^{70}$ y las inconsistencias en

${ }^{67}$ En el sentido en que Spaeth y Segal, op. cit., passim., utilizan la expresión.

${ }^{68}$ Véase en Couso y Mera, op. cit., primera parte, las evidencias a este respecto.

${ }^{69}$ Una excepción muy particular se aprecia en materias procedimentales relacionadas con la implementación de la reforma procesal penal, donde un Ministro de la Corte Suprema argumenta que "cuando la cosa está en rodaje hay que dar ciertos instructivos... porque un abogado no puede ir a La Serena y encontrarse con un procedimiento, y que después vaya a Temuco y se encuentre con otro".

${ }^{70}$ Para un Ministro de la Corte de Apelaciones de Santiago entrevistado, el juez que siga un precedente que no lo convence abandona sus deberes y podría ser acusado por ello, pues incumple su deber de ser leal sólo a la Constitución y a las leyes, negándole a las partes su derecho a ser juzgado por un juez independiente (de otra autoridad que el legislador y el constituyente). Esta curiosa preeminencia de la coherencia del juez con su "conciencia jurídica", por sobre la consistencia de los tribunales con las doctrinas que como órgano colegiado han fijado con anterioridad, asigna un valor social a la convicción personal del juez en materia de interpretación de la ley, que el sistema jurídico realmente sólo atribuye a la convicción que el juzgador adquiera al dar por establecidos los hechos. No se entiende por qué la íntima convicción jurídica del juez -que puede conducir a tantas leyes cuantos jueces haya-puede valer más que la estandarización de criterios jurídicos que permitan juzgar por igual a todos, mientras no se imponga un nuevo estándar igual de general y abstracto. 
que con cierta frecuencia incurren, ${ }^{71}$ se explican a veces -como declara un Ministro de la Corte Suprema- por errores atribuidos a la sobrecarga de trabajo, y otras veces por falta de tiempo para dejar constancia escrita de las razones de un cambio de opinión que sí está justificado y bien fundado.

Desde una perspectiva más "teórica", los jueces de la Corte Suprema y de cortes de apelaciones rechazan un sistema de precedentes en aras de la "renovación del Derecho", 72 que se vería impedida por la imposición, a los tribunales inferiores, de un deber de seguir las doctrinas establecidas por la Corte Suprema.

También da cuenta de la falta de "orientación prospectiva" de la Sala Penal su renuencia a citar sus propios precedentes. Esta práctica es poco frecuente, y llama la atención que la Sala Penal incluso ha omitido la referencia a un precedente suyo que había sido invocado por el abogado ante la respectiva Corte de Apelaciones y desconocido por ésta, frente a lo cual la Sala Penal se limita a revocar la decisión de la Corte de Apelaciones sin hacer referencia a su precedente. ${ }^{73}$ Por cierto, la Sala Penal tampoco cita los precedentes de la propia Corte Suprema cuando se aparta de ellos, incluso en el caso en que una opinión de minoría -incluida en el propio fallo- los invoca explícitamente en apoyo de su tesis. ${ }^{74}$ Por eso, no extraña que también las Cortes de Apelaciones sólo en contadas ocasiones citen los precedentes de la Sala Penal, sea que se aparten de ellos o que los sigan.

\section{Imposibilidad de seleccionar los asuntos y sobrecarga de trabajo}

Fuera de esos factores “culturales”, un elemento institucional atenta en contra de la instalación de una "orientación prospectiva” en la Sala Penal: la obligación de conocer todo recurso que se eleve ante ella, siempre que no adolezca de vicios formales que lo hagan inadmisible. Ello genera una recarga de trabajo que dificulta seriamente un estudio y fundamentación detenidos de las decisiones en asuntos complejos de errónea aplicación del Derecho y favorece la tendencia de la Sala Penal a interesarse y pronunciarse sobre el fondo del asunto en aquellos casos que no plantean problemas de interpretación jurídica. La profusión de fallos sin fundamentación, asociada a esta recarga de trabajo, es una característica de la Corte Suprema que también conspira, como se verá, con la producción de una jurisprudencia visible y susceptible de ser seguida por los tribunales inferiores. ${ }^{75}$

\footnotetext{
${ }^{71}$ Couso y Mera, op. cit., registran algunas inconsistencias con la propia opinión previa, en materias en las que, por su visibilidad, menos podría esperárselas.

${ }^{72}$ Argumento reiterado por a lo menos tres ministros de corte entrevistados.

${ }^{73}$ Véase en Couso y Mera, op. cit., el análisis de la uniformación interna de la jurisprudencia en relación con la cuestión de la inconstitucionalidad del Art. 44 de la Ley de Cuentas Corrientes Bancarias y Cheques.

${ }^{74}$ Ibid., sobre la uniformación interna de la doctrina en materia de los requisitos para la aplicación de la Ley de Amnistía.

75 "Todos los factores se enlazan, como no tenemos ninguna facultad de seleccionar lo que tenemos, y debemos resolverlo todo, y el tiempo cada día es más escaso, donde del amparo pasamos a las casaciones...", explica un Ministro de la Corte Suprema.
} 
Conscientes de este problema, algunos ministros de la Corte Suprema derechamente plantean la necesidad de una reforma que les permita seleccionar los asuntos de que conocerán ("Yo he sido un gran partidario del certiorari que tiene la Corte Suprema de Estados Unidos...”, plantea uno) o que de otra forma reduzca drásticamente el volumen de casos que conocen ("sólo deberían llegar los problemas más profundos en lo jurídico y lo constitucional; que la casación quede como casación, no como ahora que es una tercera instancia”, plantea otro). Un Ministro de la Corte de Apelaciones de Santiago propone la posibilidad de rechazar de plano recursos por "falta de fundamento" si se oponen a jurisprudencia reiterada de la Corte Suprema.

\section{Tamaño del tribunal, especialidad y permanencia de sus miembros}

La creación de la Sala Penal -y de las demás salas temáticamente especializadas- responde en teoría a una variable relevante para generar doctrinas jurisprudenciales estables en el tiempo: es un tribunal compacto, especializado en materia penal y que cuenta -más por una política interna en la Corte Suprema, que por diseño institucional- con miembros más o menos permanentes en el tiempo. ${ }^{76}$ Los (modestos) efectos de uniformación interna de su jurisprudencia alcanzados por la Sala Penal ${ }^{77}$ parecen explicarse fundamentalmente por esas circunstancias, ${ }^{78}$ sobre todo a partir del año 1998, cuando adquirió una composición más estable en el tiempo, bajo un cierto liderazgo intelectual del Ministro Cury, que tendió a darle algo más de consistencia. ${ }^{79}$ Con todo, los mecanismos empleados para asegurar la aplicación uniforme de sus tesis jurisprudenciales a nivel de la Sala Penal son, a veces, demasiado artesanales ${ }^{80}$ para ser confiables a largo plazo y, en cualquier caso, las “mayorías ocasionales”, integradas siempre por jueces con

${ }^{76}$ Un ministro de la Sala Penal de la Corte Suprema asoció la coherencia de los fallos de dicha Sala con su especialización: “...siempre hay alguien que dice que hay que hacer un nuevo sorteo, pero yo siempre me opongo, creo que eso haría correr riesgos graves, porque se cambiaría todo un criterio que ya está más o menos afiatado... en cuanto al servicio que se da a la comunidad, yo creo que es mejor (con) jueces especializados..."

${ }^{77}$ Analizados por Couso y Mera, op. cit., primera parte.

${ }^{78}$ Lo que se aprecia especialmente en el caso de la cuestión sobre la inconstitucionalidad del Art. 44 de la Ley de bancos, al comparar la dispersión de las doctrinas sostenidas por las diversas salas de la Corte Suprema con la uniformación de la doctrina aplicada por la Sala Penal tras su creación; véase Couso y Mera, Ibidem.

${ }^{79}$ Según otro miembro de la Sala Penal, la jurisprudencia "tiene importancia en la medida que la Corte Suprema o la Sala que las dicta tenga la seriedad suficiente para causar una impresión, y creo que la Sala (Penal) tiene esa posibilidad; la Sala tiene a Enrique Cury y, por ende, los fallos no son cualquier cosa..."; un prestigioso abogado penalista y profesor de Derecho penal, por su parte, mucho más crítico sobre el "pobre nivel" de la jurisprudencia de la Sala Penal acota: "salvo algunos fallos de Cury".

${ }^{80}$ Un ex Relator de la Corte Suprema explica la forma en que en la práctica se "registran" las doctrinas establecidas por una sala a efectos de tenerlas presente en el futuro cuando deben volver a fallar sobre el mismo asunto: "ellos (los Ministros) van fijando cierta doctrina que, si no se acuerdan, hay una digitadora (y) hay un relator que los ayudan, y la memoria misma de ellos; entonces es difícil perderse en lo que es su jurisprudencia; y además de eso, tienes el antecedente de que cada uno sabe lo que ha sostenido”. 
actitudes tan marcadamente "preferenciales" y nada "precedenciales" reducen el impacto que esta Sala especializada podría tener en términos de producción de una jurisprudencia estable, más aún si se tienen en cuenta los otros déficit ya indicados.

\section{Mecanismos institucionales para promover apego de tribunales inferiores a los precedentes}

Curiosamente, pese a la fuerza del mecanismo con que cuenta la Corte Suprema -el "mandante" (en el modelo de la relación mandante-agente) $-^{81}$ para procurar coherencia de las cortes de apelaciones -al agente- ${ }^{82}$ con sus precedentes y receptividad de las mismas a sus cambios de tesis, a saber, la facultad de sancionar disciplinariamente las "faltas o abusos" que los jueces de estas cortes cometieren precisamente al fallar de una forma que al tribunal superior le parece inaceptable, ${ }^{83}$ y pese a que este recurso -cuya frecuencia de empleo no fue objeto de este estudio- se percibe por los ministros de cortes de apelaciones como un factor inhibidor de la "disidencia" o incluso de la "creatividad" 84 judicial, ${ }^{85}$ su existencia no ha logrado aumentar claramente los niveles de uniformación vertical de la jurisprudencia de la Corte Suprema, ${ }^{86}$ ni siguiera a través del efecto simbólico de este agresivo medio, ${ }^{87}$ lo que puede explicarse por los déficits existentes en relación con las demás condiciones necesarias para la uniformación "vertical" de la jurisprudencia.

Entre estos déficit debe contarse el que, pese a la existencia de este extremo (y desprestigiado) medio de uniformación vertical, falte en los tribunales chilenos una doctrina clara de nulidad o anulabilidad de los fallos que se aparten del precedente, ${ }^{88} \mathrm{y}$

${ }^{81}$ Véase Songer et al., op. cit., pp. 674 y ss.

${ }^{82}$ Ibidem.

${ }^{83}$ Recurso ajeno, como se señaló más arriba, al sistema de precedentes, que se apoya fundamentalmente en la nulidad o anulabilidad de los fallos que se apartan de ellos, y no, en cambio, en el recurso a una sanción disciplinaria para sus autores.

84 “...(el ejercicio de la jurisdicción disciplinaria por parte de la Corte Suprema) inhibe a los jueces creativos, que no son obedientes. Además el más obediente tiene mayores posibilidades de llegar a la Suprema, si no te peleas con nadie”, opina un Ministro de Corte de Apelaciones.

${ }^{85}$ Esta percepción está muy extendida, y es prácticamente unánime -entre los ministros de cortes de apelaciones entrevistados- la opinión que demanda una reforma que prive a la Corte Suprema de la facultad de adoptar sanciones disciplinarias en contra de los jueces inferiores simplemente porque han fallado de forma diferente a la que la Corte Suprema considera la correcta.

${ }^{86}$ Véase Couso y Mera, op. cit., segunda parte.

87 "Yo trato que no (produzcan un efecto inhibitorio en sus decisiones las potestades disciplinarias de la Corte Suprema), pero no podría decir que nunca jamás”, expresa un Ministro de Corte de Apelaciones de Santiago; “...Sí, se inhibe (el juez, al emitir fallos, frente al riesgo de sanción disciplinaria). Nosotros tenemos especial cuidado, en las causas en que el único recurso que posee (la parte perjudicada) es la queja (disciplinaria), de averiguar cuáles son los criterios sobre las materias de la Corte Suprema, no nos arriesgamos a una sanción disciplinaria por dar la contra a la Corte Suprema”, expone un Ministro de Corte de Apelaciones de Concepción.

${ }^{88}$ Por más que ello se desprenda del sentido del recurso de nulidad por errónea aplicación del Derecho, cuyo conocimiento se entrega a la Corte Suprema en los casos en que "respecto de la materia de derecho objeto del mismo existieren distintas interpretaciones sostenidas en diversos fallos emanados de los tribu- 
la inexistencia -en subsidio de lo anterior- de un mecanismo centralizador de la práctica de apartarse del precedentes, como el que impone -en Alemania- al tribunal inferior que se quiere apartar de un precedente la "obligación de presentar" (Vorlagepflicht) el asunto a un tribunal superior, obligación que contribuye a uniformar la doctrina, tanto si este tribunal rechaza la nueva tesis (confirmando el precedente) como si la acoge (estableciendo un nuevo precedente que también vinculará a otros tribunales inferiores).

Lo curioso del caso es que, justamente a falta de estos otros medios de uniformación de la jurisprudencia y de fortalecimiento del valor del precedente, en la cultura de los jueces chilenos parece haberse instalado una asociación entre el sistema de precedentes y el ejercicio de la potestad disciplinaria. A ello contribuyó la situación planteada en la Corte Suprema cuando la Sala Penal, en julio de 2002, ${ }^{89}$ al tener que resolver sobre diversos recursos de queja (disciplinaria) interpuestos en contra de sendas decisiones de cortes de apelaciones que se apartaban de la doctrina fijada por la Sala Penal en determinado asunto, envió los antecedentes al Pleno de la misma Corte para que éste decidiera las sanciones disciplinarias que, en su caso, correspondía aplicar. Para la Sala Penal, en buena medida, en la cuestión se jugaba el carácter vinculante de las decisiones que ella había pronunciado al resolver recursos de nulidad por errónea aplicación del derecho, pero la suerte de esa cuestión, por la estructura del recurso planteado (queja), quedaba unida a la decisión de si correspondía sancionar disciplinariamente a los jueces que no siguieran esos fallos supuestamente vinculantes. La mayoría del Pleno de la Corte Suprema, probablemente haciéndose eco a las críticas que esta medida despierta entre los jueces de cortes de apelaciones, resolvió que no correspondía sancionarlos y, junto con ello, que las decisiones de la Sala Penal no tenían efecto vinculante sino para la causa en la que se pronunciaron, y que en ello se jugaba también la independencia de los jueces. ${ }^{90}$

Así, parece haberse instalado de alguna manera, en la cultura judicial local, esta asociación -en absoluto necesaria, ni empíricamente cierta en perspectiva comparada- entre precedentes vinculantes, control disciplinario y pérdida de independencia de los jueces. Ilustrativa de la confusión que esta asociación plantea es la opinión de un Ministro de la Corte de Apelaciones de Santiago, firme opositor del sistema de precedentes precisamente -entre otras razones- por atentar en contra de la independencia de

nales superiores" (Art. 376 del CPP), y que debe ser resuelto precisamente a través de una decisión que unifique la doctrina, de manera tal que, en el futuro, por lógica, un fallo que se aparte de esa doctrina debe ser anulable -por errónea aplicación del derecho- por el solo hecho de apartarse de aquel fallo unificador, como lo entiende un Ministro de la Sala Penal de la Corte Suprema: "en nuestra opinión, aunque no se diga eso de manera expresa, en esos casos pareciera que el fallo de la Corte Suprema debiera ser vinculante, al resolver la contradicción, y no prolongarla en el tiempo". Véase también, Mera, en Mera y Castro, op. cit., pp. 64 y ss.

${ }^{89}$ Véase supra, nota al pie 7.

${ }^{90}$ Empleando un razonamiento que en el pasado también se ha esgrimido en España (país que transita, sin embargo, hacia un sistema que reconoce el carácter vinculante de los precedentes del Tribunal Supremo; véase Couso, op. cit., pp. 3-4), y que Ruiz Miguel y Laporta, op. cit., pp. 274, califican "una concepción bizarra de la independencia judicial". 
los jueces, pero quien, consciente de la necesidad de racionalizar el trabajo de la Corte Suprema en los casos en que hay jurisprudencia reiterada, propone que se la faculte para acoger o rechazar recursos abreviadamente, cuando éstos claramente se apoyan en, o se oponen a -respectivamente- la doctrina establecida por jurisprudencia reiterada de la misma Corte, sin advertir que la facultad de acoger abreviadamente esos recursos -es decir, cuando lo recurrido es una sentencia que se apartó del precedente- en la práctica implica reconocer la anulabilidad del fallo que se aparta del precedente, por ese solo hecho, es decir, implica reconocer el carácter vinculante de este más allá de la causa en que se pronunció (siempre que su doctrina haya sido reconocida en forma reiterada).

\section{Rol de los abogados}

En Chile los abogados manifiestan un claro desinterés frente a la jurisprudencia de la Corte Suprema, sobre todo si se compara su actitud frente a ellos con la de los abogados de otros países donde son precisamente ellos quienes aseguran que los tribunales tengan en cuenta un precedente relevante, favorable a la pretensión de su cliente, o que, por el contrario, desestimen un precedente emitido para un caso que no guarda una semejanza en lo relevante con los hechos del caso actual (distinguishing). Sin embargo, es claro que esta actitud de los abogados penalistas chilenos viene condicionada por la percepción que ellos tienen acerca del escaso valor que esta jurisprudencia desempeñará en la decisión del caso, ya sea porque la pobre fundamentación de aquellos fallos da cuenta de que la Corte no tiene realmente una doctrina sólida que esté sentando un precedente ${ }^{91}$ o porque la probada inconsistencia de la Corte Suprema con sus tesis anteriores no garantiza en absoluto una regularidad para las decisiones futuras sobre el mismo asunto. ${ }^{92}$ Pero de las mismas explicaciones de los abogados se desprende que, determinante de su relativo desinterés por la jurisprudencia de la Sala Penal es la circunstancia de que para los demás tribunales chilenos -especialmente, las cortes de apelaciones- los precedentes de la Sala Penal no tendrían más fuerza que la que les da la consistencia de su argumentación, razón por la cual la invocación de una decisión de este tribunal, pobremente fundamentada, y seguramente inconsistente con otras anteriores -o futuras-, no ofrece grandes perspectivas de impactar en la decisión que una corte de apelaciones adoptará en el presente; por el contrario, fallos bien fundamentados, con una doctrina mantenida en el tiempo

${ }^{91}$ Dos prestigiosos abogados penalistas y profesores de Derecho Penal señalan, sobre este asunto, respectivamente: "en la práctica profesional no se le da mayor valor (a la jurisprudencia de la Sala Penal), no se la invoca. A ello contribuye que la jurisprudencia es de pobre nivel -salvo algunos fallos de Cury-, comparada con la que había décadas atrás... ahora los fallos son poco fundamentados”; y “...no estoy dispuesto a citar jurisprudencia que me parece muy pobre o afirmaciones jurisprudenciales en el aire, entonces, si no hay un fallo muy bueno yo prefiero apartarlos de mis alegatos...".

${ }^{92}$ Un prestigioso abogado penalista y profesor de Derecho Penal explica sobre este problema: "En general, uno no tiene conocimiento detallado (de la jurisprudencia penal de la Corte Suprema)... por el problema de acceso... y, por otro lado, porque (el hecho de) que te encuentres con un fallo no significa nada, puedes encontrarte con un fallo que dice que la estructura del delito es de omisión, y nosotros sabemos que la Sala Penal mañana no va a seguir ese criterio...". 
sí se convierten en un argumento un poco más valioso para los abogados, en la medida que lo son para las cortes de apelaciones. ${ }^{93}$

\section{Otras condiciones del "sistema de monitoreo" del seguimiento "vertical" de los precedentes}

Si los precedentes de la Sala Penal han de cumplir un papel en la decisión de casos futuros, cualquiera que sea el grado de "fuerza" o "influencia" que se les confiera en ella, deben cumplir con ciertas condiciones básicas de "visibilidad", tanto para los abogados -que parecen ser el vehículo fundamental que los ha de transportar a la decisión de los casos futuros- como para los tribunales inferiores, en incluso para la propia Sala Penal, en el futuro. Por otra parte, el régimen de recursos debe posibilitar que las decisiones de tribunales inferiores contrarias a los precedentes de la Corte Suprema sean impugnables ante los tribunales superiores por esa razón.

Respecto de la "visibilidad" de los precedentes, en Chile es relativamente reciente, pero cada vez más sistemática, la práctica de publicación de fallos de los tribunales superiores. Sin embargo, hasta el año 2005 los abogados y los jueces manifestaban tener problemas de acceso a dicha jurisprudencia. ${ }^{94}$

Con respecto a las posibilidades de recurrir para ante los tribunales superiores, para hacer valer los precedentes de la Sala Penal en casos en los que se los ha ignorado, el recurso de nulidad por errónea aplicación de derecho es, en principio, un camino apropiado, que permite a los abogados ejercer su rol dentro del "sistema de monitoreo" de la

${ }^{93}$ Reveladora es la opinión de un ministro de Corte de Apelaciones, cuando se le pregunta sobre la necesidad de ofrecer a los ministros de cortes de apelaciones medios de acceso electrónicos a los fallos de la Sala Penal: "no tenemos ningún interés en tener una base de datos de toda la jurisprudencia, simplemente recopilar lo interesante de un fallo...”. En Couso y Mera, op. cit., passim, se analiza precisamente el relativo impacto que, en contados casos, ha tenido la jurisprudencia reiterada de la Sala Penal en materias visibles, tanto para los abogados como para los ministros de Cortes de Apelaciones.

${ }^{94}$ Si bien un abogado penalista y profesor de Derecho manifiesta tener problemas de acceso a la jurisprudencia porque las colecciones físicas y electrónicas son insuficientes y "el sistema es bastante imperfecto", para los ministros de las cortes de apelaciones entrevistados el problema parecía ser más elemental, en la medida que o no contaban a esa fecha con acceso institucional a dichas colecciones ("Lamentablemente no tenemos ningún acceso a jurisprudencia en línea”, plantea un ministro de Corte de Apelaciones), o no tenían en absoluto adquirida las habilidades prácticas para consultar las colecciones electrónicas, por lo que dependían por completo de la información que otros les entregaran (el mismo Ministro agrega "además, yo creo que sería una pérdida de tiempo (ofrecer acceso en línea a los ministros de Corte); te voy a contar una anécdota: cuando comenzamos a computarizar esta cosa, nos costaba mucho conseguir un computador, traíamos diez computadores, pero siempre quedaba un ministro sin uno, y quería tenerlo, obviamente en ese gallito los que perdían eran los de secretaría, y cuando el ministro tenía el computador, ni lo ocupaba... entonces aquí el problema sería el mismo: jurisprudencia para todos, gastamos una fortuna, pero ¿cuántos la van a leer?"; otro ministro de Corte de Apelaciones, dando cuenta de su propia distancia sobre estos medios de consulta en línea, explica: "A través de la bibliotecaria (accedo a la jurisprudencia de la Sala Penal, a ella le pido yo si hay fallos sobre tal materia... Mire, justamente recién nombraron a una Ministra nueva, y ella se preocupó, porque ella sí que se mete a Internet y ve todos los fallos de la Suprema; ella propuso que nos hicieran un cuadernillo a cada uno con todos los fallos que vayan saliendo en cierto sentido... pero ordenados por materias... y en materia penal creo que también hay alguna revisión”). 
uniformación vertical de la jurisprudencia. Las variables más importantes, sin embargo, parecen tener que ver con la existencia o no de recursos profesionales para estudiar y conocer los precedentes y poder efectivamente destinar tiempo y capacidades profesionales para plantear los recursos y alegarlos; en esta materia no cabe duda que la creación de los dos grandes litigantes institucionales, el Ministerio Público y la Defensoría Penal Pública, con unidades de estudio capaces de identificar los precedentes más favorables a sus tesis, así como con importantes recursos profesionales para interponer y alegar los recursos de nulidad necesarios para reclamar de los "errores de Derecho" cometidos por los fallos que ignoren dichos precedentes, ofrece condiciones nuevas para que los litigantes ejerzan su rol de "alarma de fuego" 95 en tales casos. Por cierto, sólo tendrán incentivos para desempeñar ese rol en la medida que se instale con más claridad una doctrina sobre la anulabilidad de los fallos que se aparten del precedente.

Con todo, el camino hacia el establecimiento de un sistema de precedentes más "visibles" y, por ello, capaces de servir a la uniformación vertical de la jurisprudencia, pasa también por un mayor desarrollo del razonamiento judicial, primero a través de una formulación clara de los precedentes en sentido estricto (las ratione decidendi o rules), lo que exige una fundamentación, en los fallos de la Corte Suprema, que dé cuenta suficiente de los hechos de la causa a los que se refiere su decisión, y que permita siquiera inferir las "razones justificatorias" de tal decisión en casos como ese. Sólo así podrán los tribunales inferiores, y la propia Corte Suprema, en casos futuros, identificar correctamente si hay o no "semejanza en lo relevante" en los hechos, de modo de aplicar a ellos la regla precedente o, por el contrario, "distinguir" el nuevo caso del anterior, dejando de aplicar, por tanto, un precedente que no fue establecido para este tipo de situaciones 96

${ }^{95}$ Songer et al., op. cit., p. 693.

${ }^{96}$ Un ejemplo de precedente tomado de la Sala Penal permite explicar el problema: el conocido precedente de este tribunal, redactado por el Ministro Cury, sobre las condiciones bajo las cuales corresponde calificar a las "casas de veraneo" como un "lugar destinado a la habitación" a los efectos del Art. 440 del Código Penal. El precedente (establecido por sentencia de casación en el fondo Rol 2.220-00, de la Sala Penal, con fecha 21 de agosto de 2000) se aparta explícitamente de la tesis de conocidos tratadistas nacionales (Etcheberry y Novoa) que califican esos lugares como "no habitados" si el robo se produce fuera de la temporada estival, y establece una interesante distinción, fundada en las mismas razones justificatorias invocadas por esos tratadistas: " $6^{\circ} \ldots$ la punibilidad superior atribuida al robo (con fuerza en las cosas) en "lugar destinado a la habitación” se debe a que este delito es, en verdad, un atentado pluriobjetivo, pues por una parte ataca la propiedad y, por otra, genera un riesgo para la seguridad de los moradores, los cuales en cualquier momento podrían regresar, encontrarse con el o los autores, y verse consiguientemente expuestos a una agresión a su vida o integridad corporal. . $7^{\circ} \ldots$ la distinción entre el lugar destinado a la habitación y el no habitado tiene que efectuarse sobre una base valorativa, pues requiere evaluar hasta qué punto cabe temer, en las distintas clases de sitios, la posibilidad de un encuentro entre el hechor y terceros ... $8^{\circ}$ Que si bien es cierto que las casas de veraneo suelen permanecer vacías por períodos de tiempo relativamente prolongados, la referida posibilidad es más bien alta y se ha vuelto progresivamente mayor, a causa de una serie de circunstancias... Por una parte, el desarrollo de las vías y los medios de comunicación ha determinado que dichos lugares ya no sean ocupados solamente en una temporada determinada, sino que sus propietarios o personas vinculadas a ellos puedan llegar, sea para hospedarse en ellos, sea para visitarlos, sea incluso para inspeccionarlos, en diferentes oportunidades del año y con una frecuencia cada vez mayor... $9^{\circ}$ Que, por lo razonado en el considerando anterior, esta Corte estima que, contra lo argumentado por una parte ciertamente autorizada de la doctrina, ha de concluirse que los lugares en examen han de consi- 
(expediente que no niega, sino que también ¡reconoce! valor al precedente). ${ }^{97}$ Mientras no se logre ese desarrollo será más difícil que las decisiones de la Sala Penal sean realmente (valorativamente) consistentes entre sí y ofrezcan pautas (rules) claras a las cortes de apelaciones y a los tribunales penales que éstos puedan inteligentemente (es decir, comprendiendo sus razones justificatorias) seguir.

\section{Conclusiones}

El relativo fracaso de la Sala Penal de la Corte Suprema en el cumplimiento de su objetivo de uniformar la jurisprudencia se asocia a los déficit de condiciones culturales, institucionales y de técnica jurídica asociados, en la experiencia comparada, al logro de esa misión. La existencia de una sala especializada en materia penal, con miembros más o menos estables en el tiempo, es una sola de esas condiciones que no logra, por sí sola, compensar el déficit de aquellas otras condiciones.

derarse "destinados a la habitación" (considerandos $6^{\circ}, 7^{\circ}, 8^{\circ}$ y $9^{\circ}$ ). La rule establecida en este precedente considera destinada a la casa de habitación en el caso planteado bajo una razón justificatoria acertada, pero que se entiende sólo deficientemente por falta de referencias más claras por parte del fallo a la base fáctica, que sólo indirectamente se puede inferir: se trataba de un robo a una casa de veraneo en el litoral central de Chile (el juzgado del Crimen que falla en primera instancia es de Casablanca), deshabitada, durante el mes de abril, datos esenciales para entender por qué, bajo la razón justificatoria invocada (el robo en lugar destinado a la habitación es un delito pluriofensivo, que castiga el peligro concreto -hay que evaluar "hasta qué punto cabe temer... un encuentro"- para la vida o integridad corporal) se calificó a la casa de ese caso como "destinada a la habitación". Esa falta de referencia a los hechos concretos de la causa, vuelve a la rule inconvenientemente abstracta, lo que dificultará en casos futuros discriminar cuándo hay semejanza en lo relevante y cuando no. Ahora bien, cuando la Sala Penal tuvo que plantearse en un caso posterior (en sentencia de casación en el fondo 1.522-01, de fecha 19 de julio de 2001), si correspondía aplicar la rule establecida en el caso precedente, nuevamente lo hizo en forma abstracta, y simplemente reiteró la rule para una situación fáctica (que sólo se descubre consultando los fallos de primera y segunda instancia) que, sin embargo, parece más bien "distinta en lo relevante": se trataba de un robo cometido un día 30 de octubre de 2000, en una cabaña deshabitada y cerrada con candados, situada en el kilómetro 68 del camino a las Termas de Chillán, aparentemente destinada a un uso como cabaña de montaña (se robaron parkas de nieve), sin que existiese un cuidador específico de la cabaña, sino uno destinado a un predio mucho más amplio donde hay varias cabañas, y que no tiene en dicho lugar más posibilidades de encontrarse con los autores del robo que en un complejo industrial o agrícola no destinado a la habitación; pero el fallo no menciona ninguna de estas circunstancias, pese a que podrían permitir "distinguir" el caso, sobre la base de la misma razón justificatoria del precedente (razón que, de hecho, en este nuevo fallo se reproduce textualmente, literalmente con los mismo puntos y comas, lo que sugiere que sencillamente se empleó el mismo archivo computacional). Con ello, el precedente, que debería construirse como una regla relacionada con una cierta base fáctica acotada de acuerdo con la razón justificatoria, ahora queda completamente abstraído de aquella referencia fáctica: las casas de veraneo (o las cabañas de invierno) ahora son (¡siempre?) "lugares destinados a la habitación”, lo que ciertamente no corresponde a las razones justificatorias del precedente. Clarificadora es, a este respecto, la explicación de un ministro de la misma Sala Penal, que concurrió al precedente pero tampoco estuvo presente para la dictación de este segundo fallo: "hay que atender a las circunstancias concretas, para ver si realmente el autor puede encontrarse con personas, si los habitantes viajan con frecuencia, etc., esos factores deben ser los que al final deben resolver".

${ }^{97} \mathrm{Si}$ bien un uso excesivo de la práctica del distinguishing puede traducirse en una manipulación del precedente, que realmente oculta que se desconoce su valor; véase, al respecto, Couso, op. cit., pp. 13-15. 
Entre las condiciones más importantes que deberían crearse se cuenta el establecimiento de una doctrina clara sobre la anulabilidad de los fallos que se aparten de los precedentes de la Sala Penal. Ello sería más fácil de conseguir si se despeja la confusa concepción -a la que contribuyó la situación que condujo a la decisión del Pleno de la Corte Suprema en julio de 2002- que vincula la obligación de seguir los precedentes con la jurisdicción disciplinaria y la independencia de los jueces. Por ello, la deseable eliminación de la jurisdicción disciplinaria de la Corte Suprema -que sí limita la independencia interna de los jueces- es una meta positivamente asociada al fortalecimiento del valor de los precedentes, vía anulabilidad de las decisiones que los desconozcan.

Otra condición fundamental es el necesario perfeccionamiento del razonamiento judicial y de la tarea de fundamentación de las sentencias en la Sala Penal, sin lo cual difícilmente se producen precedentes comprensibles, susceptibles de ser seguidos con sentido, lo que incluye la posibilidad de no aplicarlos cuando no se da "semejanza en lo relevante". Esta condición depende, en gran medida, de la reducción de la carga de la Sala Penal. Esta reducción, si ha de ser eficiente en relación con el objetivo buscado, no debería pasar por aumentar el tamaño de la Sala -creando secciones o paneles, como en otros países- sino por facultar a este tribunal para seleccionar los casos de los cuales conocerá. Una alternativa es el establecimiento de procedimientos abreviados -sumarísimos- para acoger o desestimar recursos, cuando a favor o en contra de ellos existen precisamente precedentes de la propia Sala, que deben considerarse vinculantes (los que resuelvan recursos de nulidad por errónea aplicación del Derecho), lo que implica, una vez más, aceptar que esos precedentes son vinculantes.

Por su parte, las variables asociadas al rol de los abogados y a un adecuado funcionamiento del "sistema de monitoreo" del seguimiento de los precedentes en su dimensión "vertical", como la "visibilidad" de los precedentes de la Sala Penal y la posibilidad efectiva de las partes de recurrir cuando se desconozcan, en años recientes han mejorado claramente sus condiciones de posibilidad, con los avances de las tecnologías de la información y la reforma procesal penal.

Con todas esas condiciones, la Sala Penal -que debería seguir integrada por miembros especializados, estables en el tiempo- con seguridad cumpliría en forma mucho más satisfactoria su misión de uniformar la aplicación del Derecho, dando certeza jurídica y un tratamiento jurídico más igualitario a los ciudadanos.

\section{BIBLIOGRAFÍA}

Alexy, R. / Dreier, R., "Precedents in the Federal Republic of Germany", en MacCormick / Summers (Eds.), en Interpreting Precedents. A comparative Study, Aldershot-BrookfieldSingapore-Sydney: Ashgate/Dartmouth, 1997.

BANKowski et al., "Precedents in the United Kingdom" en MacCormick / Summers (Eds.), Interpreting Precedents. A comparative Study, Aldershot-Brookfield-Singapore-Sydney: Ashgate/Dartmouth.

Couso, J., "El uso de precedentes en materia penal: retórica y realidad en perspectiva", en Revista General de Derecho Penal (www.iustel.com, RGDP), No 5, mayo de 2006, pp. 5 y ss. 
Couso, J. y Mera, J., "El rol uniformador de la jurisprudencia de la Sala Penal de la Corte Suprema. Estudio empírico", en Ius et Praxis, Vol. 1, 2007 (en prensa).

Granados Pérez, C. (Ed.), Acuerdos del Pleno de la Sala Penal del T.S. para unificación de la jurisprudencia. Años 2001-2002, $2^{a}$ edición, actualizada y ampliada, Valencia: Tirant Lo Blanch, 2003

Hassemer, W., Fundamentos del Derecho penal, traducción de Arroyo Zapatero y Muñoz Conde, Barcelona: Bosch, 1994.

Kaplan, J., Weisberg, R., Binder, G., Criminal Law. Cases and Materials, New York: Aspen, 2000.

MacCormick, N. y Summers, R. (Eds.), Interpreting Precedents. A comparative Study, AldershotBrookfield-Singapore-Sydney: Ashgate/Dartmouth, 1997.

Marshall, G., "What is Binding in a Precedent", en MacCormick / Summers (Eds.), Interpreting Precedentes. A comparative Study, Aldershot-Brookfield-Singapore-Sydney: Ashgate/Dartmouth, 1997.

Mera, J., "La Corte Suprema y el establecimiento de precedentes en materia penal", en Mera, J. y Castro, A., Jurisprudencia penal de la Corte Suprema, LexisNexis, Santiago, Chile, 2007.

NaucKe, W., Strafrecht. Eine Einführung, 7ª ed., Neuwied-Kriftel-Berlin, 1995.

Peczenik, A., "The Binding Force of Precedents", en MacCormick / Summers (Eds.), Interpreting Precedents. A comparative Study, Aldershot-Brookfield-Singapore-Sydney: Ashgate/Dartmouth, 1997.

Roxin, C., Strafrecht. Allgemeiner Teil, Band. I. Grundlagen. Der Aufbau der Vebrechenslehre, 2a ed., München: Beck, 1994.

Ruiz Miguel, A., Laporta, F. J., "Precedent in Spain", en MacCormick / Summers (Eds.), Interpreting Precedents. A comparative Study, Aldershot-Brookfield-Singapore-Sydney: Ashgate/ Dartmouth, 1997.

Songer, D., Segal, J., Cameron, Ch., "The Hierarchy of Justice: Testing a Principal-Agent Model of Supreme Court - Circuit Court Interactions", en American Journal of Political Science, Vol. 38, No 3 (agosto de 1994), pp. 673-696.

Spaeth, H., Segal, J., Majority Rule or Minority Will. Adherence to Precedents on the U.S. Supreme Court, Cambridge University Press, 1999.

TARuffo, M., "Institutional Factors Influencing Precedents", en MacCormick / Summers (Eds.), Interpreting Precedents. A comparative Study, Aldershot-Brookfield-Singapore-Sydney: Ashgate/Dartmouth, 1997. 